\section{AN AMPUTATION RETRACTOR.}

\section{O. O. COOPER, M.D.}

Chief Surgeon the Hinton Hospital. IIINTON, W. VA.

For years in doing amputations $I$ have felt the need of some sort of efficient retractor to take the place of the two-tailed or three-tailed cloth retractor commonly used. The cloth sometimes holds the soft parts away from the saw, but frequently does not, the consequence being that the muscles are shredded or bruised enough to cause sloughing, or, on the other hand, the bone is not sawed off high enough the first time.

No instrument catalogue that I know of shows an amputation retractor of any sort, and the surgeons I

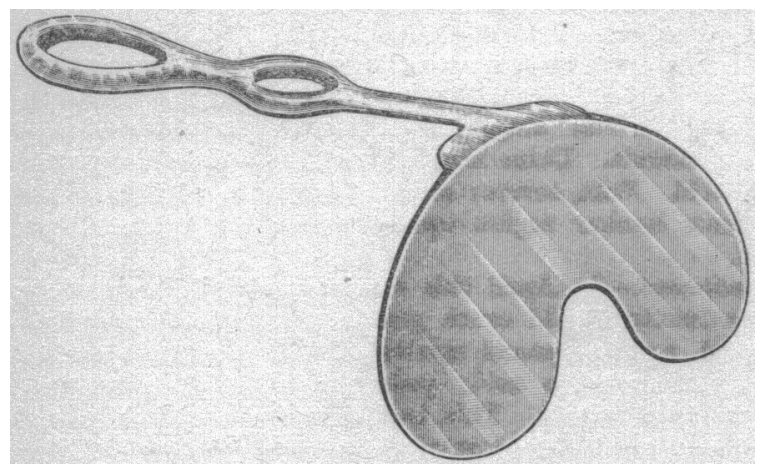

Fig. 1.-The amputation retractor.

meet have not heard of such a device, so, as far as I know, I have the only pair of amputation retractors in existence. At first I used two kidney-shaped pieces of sheet copper cut out by hand. By overlapping these around the bone and bending them a little at the periphery to keep one's fingers away from the saw the success of the idea has been demonstrated in numerous amputations. Recently I asked Max Wocher \& Son, Cincinnati, to follow up my idea and make me a pair of retractors with convenient handles. The cuts show the result of their efforts, with which I am well pleased.

The instruments are used in pairs and each consists of a blade to which a handle is rigidly attached at right

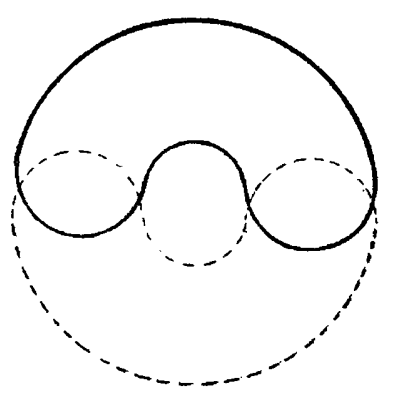

Fig. 2.-The overlapping of blades and the opening left for the bone. angles. The convex edge of the blade is a part of a circle six or seven inches in diameter. The concave edge is part of a circle one and a half inches in diameter, gradually widening. The handles are six and a half inches long and attached to the stump side of the blade so as to leave the saw side of the blade smooth. In use, the blades are applied around the bone opposite each other and then overlapped until they fit the bone snugly, when the desired retraction can be made. They will fit a bone of any size, or two bones of different sizes, as in the leg or forearm. By overlapping the blades at various angles the shape of the opening can be modified at will.

The Safe Kind of Whisky.-Dr. Wiley, of the Department of Agriculture, according to Harper's Weekly, says that the safe kind of whisky is that which is bottled; "the records show that whisky left in a bottle has never injured ang one seriously."

\section{BITE OF A POISONOUS SPIDER, LATRODEC- TUS MACTANS.}

ALEXANDER L. HODGDON, M.D.

Formerly Professor of Nervous Diseases and Diseases of the Mind, Marylanđ̃ Medical College, Baltimore.

PEARSON, MD.

The toxic qualities of the spider that is known as Latrodectus mactans are not, I believe, generally known. An appropriate name for the spider would be the " $T$ and dot" spider, as the specimen I have seen was coal black with a red $\mathrm{T}$ and red dot.

Some weeks ago I was called to see a man who, pulling on his boot, had pressed on one of these spiders with the side of his foot. The spider's bite at the time caused him but little pain or inconvenience. About twenty-five minutes after being bitten, however, acute and agonizing pains occurred all over the body, being particularly severe in the region of the chest. Aqua ammoniæ was applied locally and also administered, well diluted, internally, and previous to my arrival the patient had taken considerable whisky. Morphin sulphate, strychnin sulphate and nitroglycerin were administered hypodermically, and while the latter two drugs may have helped his condition I believe the morphin was of much greater benefit. For about forty-eight hours the symptoms were most severe, the most acute pains lasting for about eight hours; the man did not feel entirely well for about ten days.

It would seem from this case that the Latrodectus mactans must secrete a very concentrated poison which acts, when absorbed, as a direct irritant to the sensory nerves. I am interested to know just what the active principles of this poison are.

[Comment: The group of animals referred to belongs in the same subkingdom as the insects, from which they differ, however, in important characters. Several species have gained considerable reputation in medicine. Probably the most noted spider in this respect is Tarantula fasciventris of Italy, the bite of which was popularly supposed to cause the disease tarantismus or tarantula dance. Another noted spider is Latrodectus malmignatus, which is reported to have produced such fear in Spain in 1830 and 1833 that farmers hardly dared to leave their houses. An American species, Phydippus tripunctatus, is reported as causing, by its bite, a swelling, accompanied by great pain, itching and inflammation; chilliness and fever succeed each other in rapid succession and in children and in weak persons convulsions may result; the pain is said to last several days and to disappear only after free perspiration. The so-called "bird spiders" of the tropies are nocturnal animals feared because of their poisonous bites, which are very painful, but probably not so dangerous as claimed. Aname hentzii is a bird spider or tarantula sometimes found in the eastern states, and $A$. rileyi is a California species with a still less savory reputation. In 1902 Dr. H. W. Crause published in the Transactions of the State Medical Association of Texas accounts of a number of cases of spider bites observed in Texas. Latrodectus mactans has been charged with numerous serious bites in this country, and while some cases have been alleged to end fatally, many of the accounts lack sufficient details to justify any valid judgment. Dr. L. 0 . Howard has shown that at least some of the cases may have been due to bites of the piratine bugs. Some cases of very severe bites due to $L$. mactans seem, however, to be well established. It is particularly on the glans penis that persons are bitten, when in box privies. -ED.] 